\title{
Accelerator Be-Target Neutron Sources \\ for the CTR Materials Program
}

\author{
P. J. Persiani
}

\section{Argonne National Laboratory}

\section{October 1973}

\begin{abstract}
This report was prepared as in account of work sponsored by the United States Government. Neither the United States nor the United States Atomic Energy Commission, nor any of their employees, nor any of their contractors, subcontractors, or their employees, thetr contractors, subcontractors, or thei employees, makes any warranty, express or implied, or assumes any legal liability or tesponsibility for the accuracy, completeness or usefulness of any information, apparatus, product or process disclosed, or represents that its use
\end{abstract} would not infringe privately owned rights. 


\section{TABLE OF CONTENTS}

\section{ABSTRACT}

1. Introduction

2. Target Yields and Energy Distribution

3. Accelerator - Target Systems

4. Cyclotron Improvements

5. Remarks 


\author{
Accelerator Be-Target Neutron Sources \\ for the CTR Materials Progran \\ P. J. Persiani \\ Argonne National Laboratory \\ Argonne, Illinois 60439 \\ October 1973
}

\begin{abstract}
A preliminary assessment is presented of the potential for utilizing existing accelerator Betarget systems in the CTR Materials Progran. The considerations are aimed to partially satisfy the progranimatic near-term phase of the technology program.
\end{abstract}

\title{
1. Introduction
}

This brief report is a preliminary assessment of the potential for utilizing existing and/or modified accelerator Be-target systems in the CTR materials progran. The systems are considered in the context of the near-term meeds of the technology progran for: neutron intensities in the range of $>10^{12}$ to $>10^{13} \mathrm{n} / \mathrm{cm}^{2}-\mathrm{sec}$; neutron spectra much harder than the fission or spallation type spectrum; and neutron energy distribution width much narrower than spallation or evaporation target system such as obtained in LAMPF ( $800 \mathrm{meV})$ and BLIP (200 HeV) which give a broad distribution into the very high-energy region.

Depending on the specific objectives of the various miterials program, the neutron energy spectra of interest to CTR range from a sharply defined peaked distribution at $14 \mathrm{MeV}$, to a variety of spectra from $14 \mathrm{Mal}$ down to the keV and eV region wich are characteristic of the neutronic environment 
anticipated in fusion reactors. Ideally it is advantageous to develop a neutron source facility with a sharply peaked distribution at $14 \mathrm{MeV}$ and a designed.in "spectrum tailoring" capability.

The deuteron-beryllium stripping and other neutron producing reaction rates, thick tarjet neutron yield, energy spectra and angu?ar distribution for 20-40 MeV ion-beam energies would allow limited preliminary studies of CTR interest in volume-integrated and surface radiation effects with neutron energies in the neighborhood of $14 \mathrm{MeV}$ and a somewhat broad energy half-width.

\section{Target Yields and Energy Distribution}

The currently available data on the neutronics of thick beryllium target is most adequate for this preliminary assessment. The data on light-element targets are contained in Refs, 1-12. For deuteron energies of $20 \mathrm{MeV}$ and $40 \mathrm{MeV}$, estimates of neutron yield value for beryllium at the target surface are approximately $y_{n}=0.02$ to $0.06 \mathrm{n} / \mathrm{d}$, respectively. These values are averaged extrapolations from low energy data, using the energy dependence to exponent powers of 1.5 to 1.7. The above total yields are somewhat uncertain so that the actual target total yields for specific accelerator-energy systems should be subjected to direct measurements following similar techniques to those developed in Ref. 2-7.

A sensitive measure of merit in assessing accelerator and lightelement target concepts, is the strongly angular-dependent neutron-energy spectrum that will be available to the experimenter. For beryllium targets, the "mean" (or modal) energy of the forward-direction neutrons is about 0.4 of the incident deuteron energy (see Refs. $2,4,5,7$ ). The average energies of the emitted neutrons are approximately 6,8 , and $15 \mathrm{HeV}$ 
for deuteron energies of 16,20 and $40 \mathrm{MeV}$, respectively. For deuteron energies greater then $5 \mathrm{MeV}$ and thick target systems, the neutron spectra will be broad and ranging continuously from the eV region and extunding to an energy several MeV higher than the incident deuteron energy. For example the upper energy range of the neutron distribution lies in the $20 \mathrm{MeV}$ region for $16 \mathrm{MeV}$ incident deuterons. Nevertheless, the neutron energy sperara resulting from the $(d, B e)$ interactions at low deuteron energies ( $<50 \mathrm{MeV}$ ) have a much narrower energy spread than the neutron spectra resulting froin predominantly evaporation processes occurring from (d,Be) reactions at deuteron energies of $>100 \mathrm{MeV}$.

The emitted neutrons are strongly forward-biased with the energyspectrum-broadening becoming more pronounced at angles away from the forward direction, and at increasing deuteron energies. An example of the angular dependence of the energy spectra is given in Fig. 1 from measurements at 8.3 and $16.0 \mathrm{MeV}$ deuteron energies reported in Ref. 4, and Fig. 2 for $18 \mathrm{MeV}$ deuteron energy from Ref. 3.

In Figs. 1 and 2 are included the estimates of the neutron energy half-widths of $r_{\frac{1}{2}}=5,10$, and $10 \mathrm{MeV}$ at deuteron energies of $8.3,16.0$ and $18 \mathrm{MeV}$, respectively. At the higher deuteron energies of 40 and 54 $\mathrm{MeV}$, the neutron energy spectrum is broadened to a half-width of approximately $r_{\frac{1}{2}}=17 \mathrm{MeV}$. These estimates were made from measurements reported in Ref. 7 and included in Table 7 , and Figure 3.

The energy distribution will also be dependent on the target design which will be influenced by the heat dissipation requirements of the target system. 

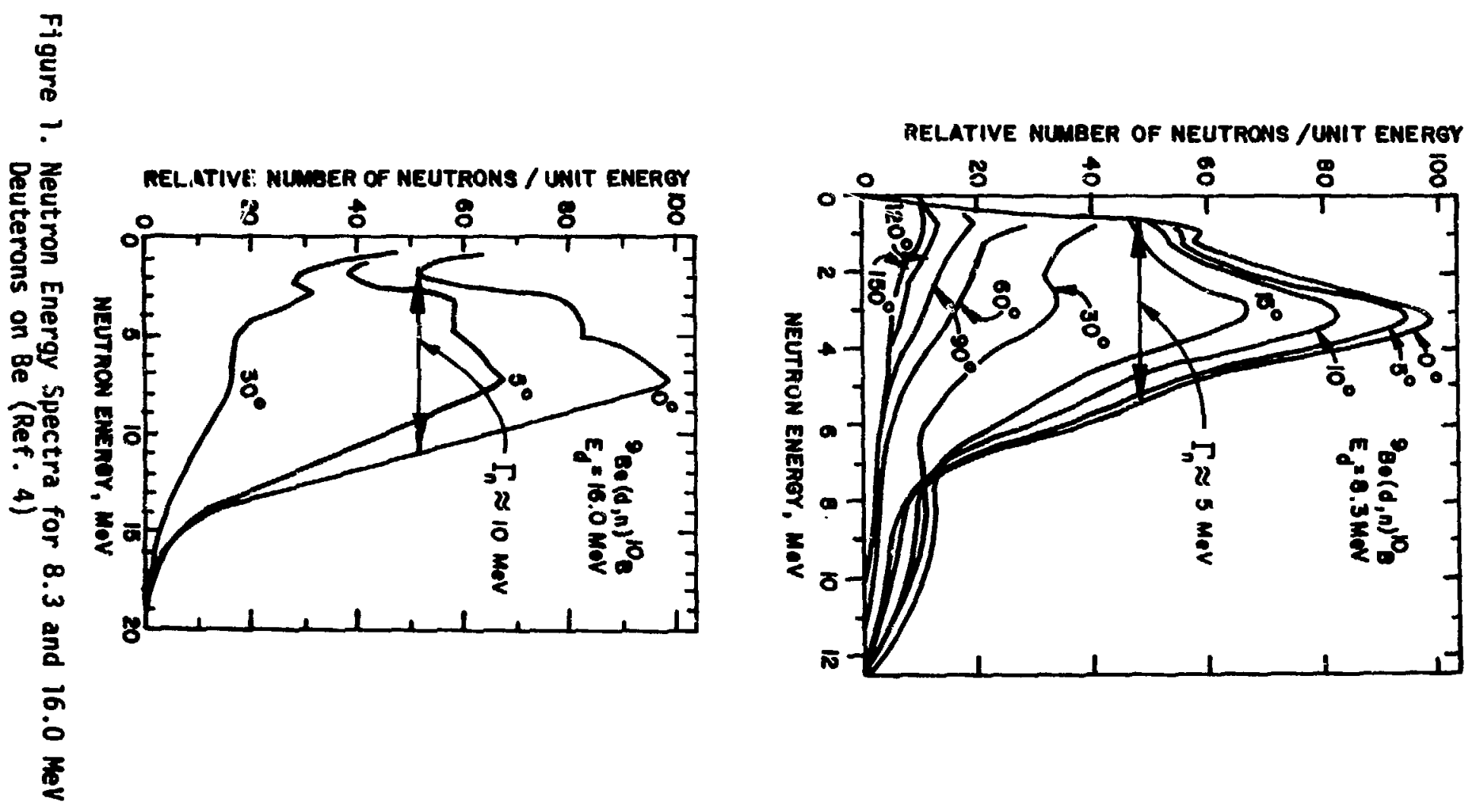


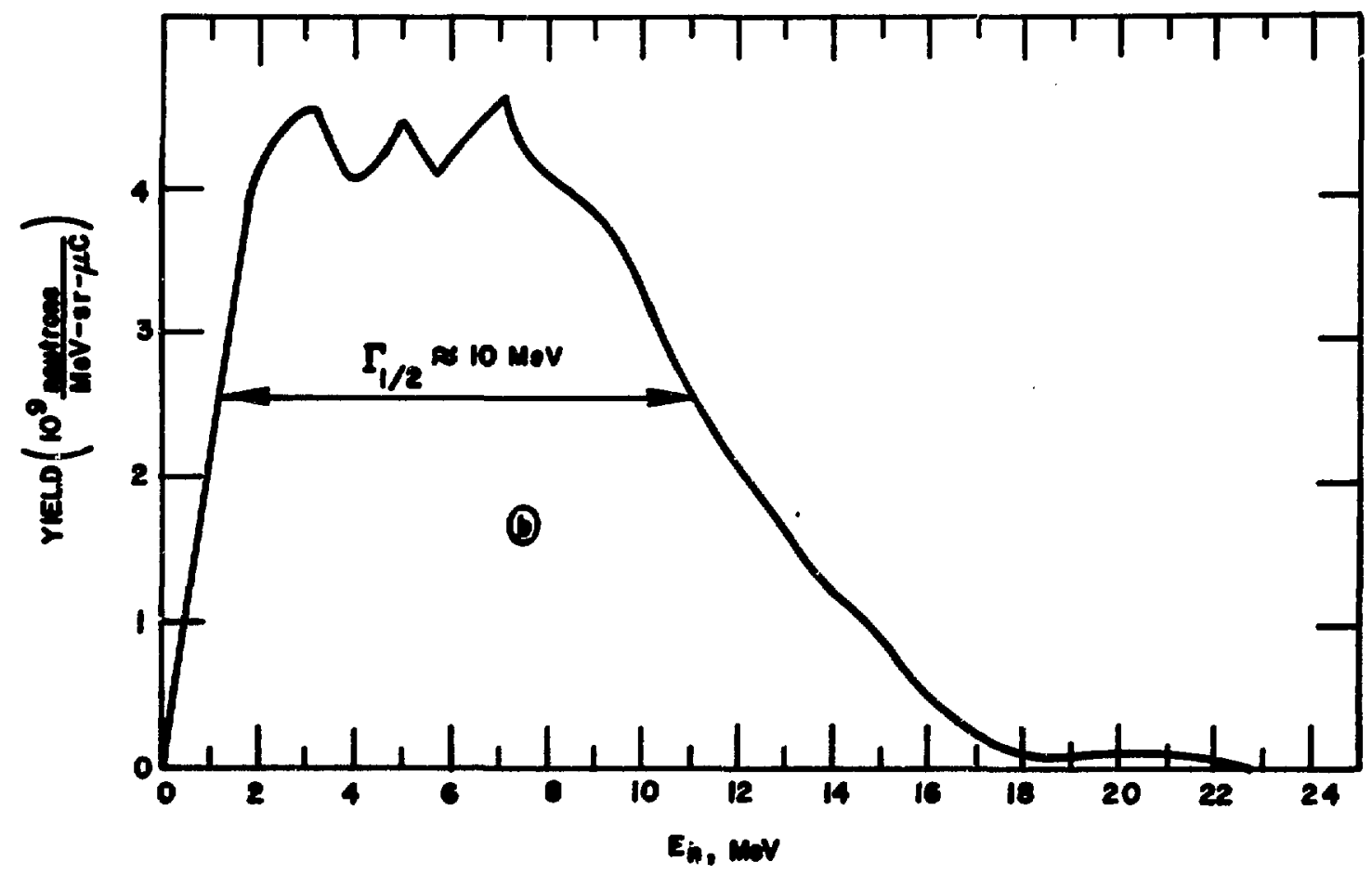

Figure 2. Neutron Energy Spectrum for $18 \mathrm{MeV}$ Deuterons on Be (Ref. 3) 
TABLE 1

Measured Yields of Neutrons Produced in the Forward Direction by Stopping 40 and $53.8 \mathrm{MeV}$ Deuterons in Thick Be Targets (Ref. 7)

\begin{tabular}{|c|c|c|}
\hline \multirow{2}{*}{$\underset{(\mathrm{MeV})}{\mathrm{E}}$} & \multicolumn{2}{|c|}{ Deuteron Energy (MeV) } \\
\hline & 40 & 53.8 \\
\hline $\begin{array}{l}11.5 \\
12.5 \\
13.5 \\
14.5 \\
15.5 \\
16.5 \\
17.5 \\
18.5 \\
19.5 \\
20.5 \\
21.5 \\
22.5 \\
23.5 \\
24.5 \\
25.5 \\
26.5 \\
27.5 \\
28.5 \\
29.5 \\
30.5 \\
31.5 \\
32.5 \\
33.5 \\
34.5 \\
35.5 \\
36.5 \\
37.5 \\
38.5 \\
39.5 \\
40.5 \\
41.5 \\
42.5 \\
43.5\end{array}$ & $\begin{array}{r}106 \\
117 \\
121 \\
148 \\
145 \\
130 \\
132 \\
134 \\
124 \\
108 \\
95 \\
81 \\
68 \\
54 \\
45 \\
38 \\
31 \\
30 \\
24 \\
19 \\
14 \\
13 \\
14 \\
12 \\
10\end{array}$ & $\begin{array}{r}124 \\
158 \\
175 \\
199 \\
196 \\
208 \\
232 \\
251 \\
251 \\
260 \\
259 \\
246 \\
238 \\
219 \\
192 \\
172 \\
152 \\
140 \\
115 \\
102 \\
85 \\
76 \\
58 \\
56 \\
47 \\
46 \\
40 \\
34 \\
31 \\
27 \\
24 \\
21\end{array}$ \\
\hline
\end{tabular}

Note: The results are given in units of $10^{3} \mathrm{n} /(\mu \mathrm{C} \cdot \mathrm{MeV} \cdot \mathrm{sr})$. 


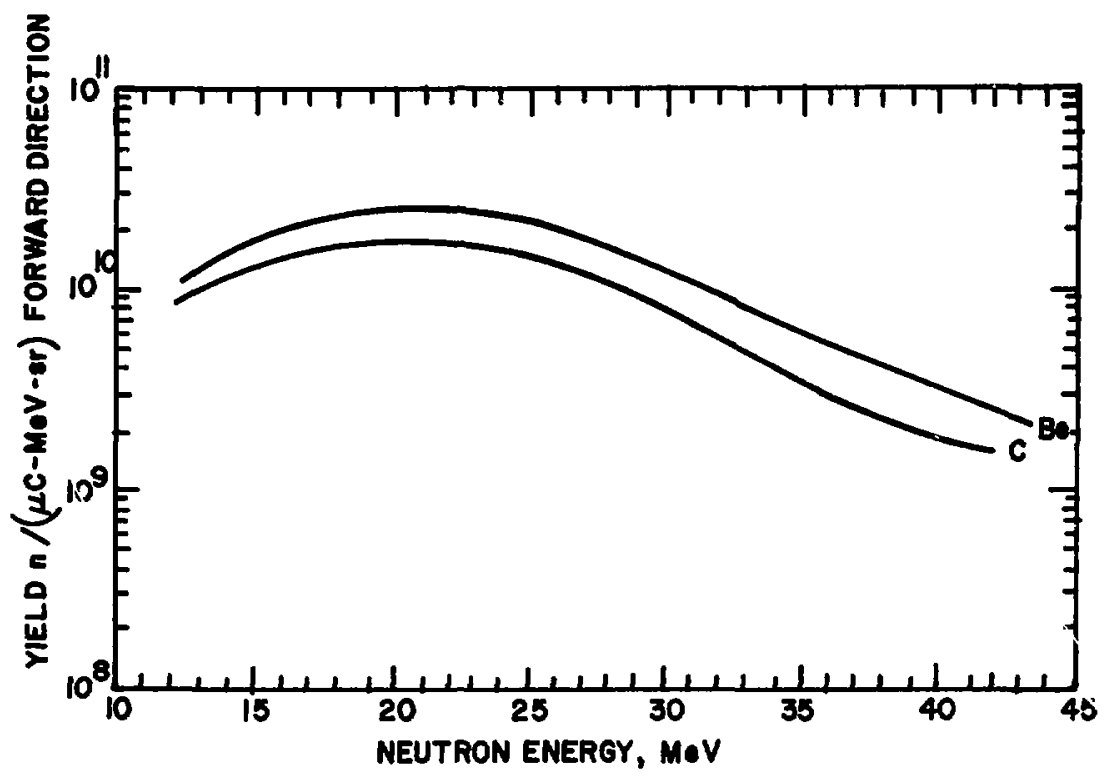

Figure 3. Neutron Yields for $53.8 \mathrm{MeV}$ Deuterons on Thick Be and C Targets (Ref. 7) 


\section{TABLE 2}

\section{Existing Cyclotron Be-Target Systems}

\begin{tabular}{|c|c|c|c|c|c|c|}
\hline $\begin{array}{l}\text { leut } \\
\text { Ene }\end{array}$ & Deu & $\begin{array}{c}\text { Deuteron } \\
\text { Beam } \\
\text { Area } \\
\left(\mathrm{cm}^{2}\right)\end{array}$ & $\begin{array}{c}\text { Deuteron } \\
\text { Beam } \\
\text { Power }\end{array}$ & $\begin{array}{c}\text { Average } \\
\text { Neutron } \\
\text { Energy }\end{array}$ & $\begin{array}{l}\text { Energy } \\
\text { Width } \\
\Gamma_{\frac{1}{x}} \\
(\mathrm{Mê})\end{array}$ & ed \\
\hline
\end{tabular}

$\begin{array}{lccccccc}\text { ORNL } & 40 & 20 & 1 & 0.8 & 15 & 17 & >10^{12} \\ \begin{array}{l}\text { U of } \\ \text { Cal. }\end{array} & 40 & 20 & 0.2 & 4.0 & 15 & 17 & \sim 10^{13} \\ \text { ANL } & 22 & 45 & 1 & 1.0 & 9 & 10 & >10^{12} \text { (at target) }\end{array}$




\section{Accelerator-Target Systems}

Cyclotrons have been utilized in accelerator-target systems for neutron production from the deuteron-beryllium reaction. For the purpose of illustration three such systems are the ORIC at Oak Ridge, the Crocker Nuclear Laboratory cyclotron at U. of California, Davis, and the ANL cyclotron. The characteristics of the accelerators and the estimated or actual neutron flux that may be available to an experimenter are included in Table 2. The estimates are based on the accelerator and beam transport systems having deuteron current capabilities of $20 \mu \mathrm{A}$ and deuteron energies of $40 \mathrm{MeV}$ for the ORIC and Crocker cyclotrons, and $45 \mu \mathrm{A}$ and $22 \mathrm{MeV}$ for the ANL cyclotron. The target total neutron yields of 0.02 and 0.06 $\mathrm{n} / \mathrm{d}$ are assumed for the 22 and $40 \mathrm{MeV}$ deuteron beams, respectively. The flux estimates include geometry factors and accounting for the forwardbiased emission but does not include factors which depend on the target and beam transport design details such as optimum positioning of the experimental apparatus for specific experiments.

This accessibility will be influenced by the design requirements of the target system to dissipate beam power if higher beam currents become available. The beam power densities have been included for the accelerators and beam transport systems as currentiy rated.

The range of 22 and $40 \mathrm{MeV}$ deuterons in beryllium is about 0.2 and $0.5 \mathrm{~cm}$, respectively. The stopping power is strongly energy-dependent and as a consequence the major fraction of the beam power is deposited in the final $10-20 \%$ of the particle track. The beam power is therefore assumed to be deposited in disc-shaped regions having thicknesses of 0.04 and 0.1 $\mathrm{cm}$, for the above deuteron energies. Within these volumes the power densities are $8 \mathrm{~kW} / \mathrm{cm}^{3}, 40 \mathrm{~kW} / \mathrm{cm}^{3}$ and $25 \mathrm{~kW} / \mathrm{cm}^{3}$ for the ORNL, $U$ of C-Davis, 
and ANL cyclotron-beryllium-target systems. The heat dissipation considerations appear to be modest for these systems at these ratings.

\section{Cyclotron Improvements}

The feasibility of upgrading the performance of existing cyclotron beam-transport systems should be given serious consideration. An increase in current at the target surface by factors of 3 or more would result in neutron fluxes in the order of $10^{13} \mathrm{n} / \mathrm{cm}^{2}-\mathrm{sec}$. At these flux levels, much of the near-term needs of the materials program may be satisfied for a modest investment in accelerator beam-transport systems modifications.

As an illustration, the ANL cyclotron beam-transport system has the potential to increase the neutron fiux output by factors of greater than 3. This possibility is dependent on the feasibility of: increasing the aperture in the focusing quadrupole magnet system; increasing the rf system loading; increasing the ion-source output; improving the beam-extraction system; designing an internal-probe target system; and replacing the Dsectors.

In a similar manner the ORNL, $U$ of C-Davis cyclotrons as well as other existing systems could be modified to increase the neutron flux output to levels which are at present not available to the CTR program.

Target-coolant systems development would also become increasingly important at these higher beam currents and the design of these systems should also be included in these efforts.

\section{Remarks}

The attempt of this report is to initiate the technical evaluation of upgrading the various subsystems in existing accelerator-target neutron 
generating facilities. The scoping evaluation in the areas presented in this report is not complete and should be extended and modified to include the specific materials programs ${ }^{13}$ which can be performed on these facilities. The resulting critique may then serve as a basis in assessing not only the feasibility of modifying the systems but whether the required effort is commensurate with the anticipated research results. The utllity of these neutron intensities and non-fusion-reactor energy distributions must eventually be based on the user's and reactor designer's evaluation that the output of these facilities is the quality output needed to make significant advances relevant to the CTR Technology progran. 


\section{REFERENCES}

1. A. Snith and $W$. Poenitz, AP-ANL, private comunication.

2. K. Porges, J. L. Snelgrove, R. Cold, A. DeVolpl, R. J. Armani and C. E. Cohn, "Thick Target Neutron Yitelds of Lithism and Beryllium Targets Bombarded with Protons and Deuterons, Applied Physics Diviston Annual Report, 1970 to 1971, ML-7910.

3. K. A. Heaver, J. D. Anderson, H. H. Barschall and J. C. Davis, "Neutron from the Banbardment of Beryllitum by Deuterons," Phys. Hed. Biol 18, 64-70 (1973). (See ilso Nucl. Sei. Eng. \$2, 35 (1973).

4. F. T. Kuchnir, 2. S. Skaggs, A. J. Elwyn, F. P. Mooring, and N. A. Frigerio, "Design of a Neutron Therapy Facility for 30 -inch Cyciotron," Proc. 6th International Cyclotron Conf., Vancouver, Canade July 18-21, 1972, p. 638.

5. V. K. Daruga and N. N. Krasnov, "Production of Strong, High-Energy Neutron Fluxes in a Cyclotron by Irradiating Thick Lithium and Beryllium Targets with 22-Mey Deuterons," Soviet At. Energy, 30, p. $493(1971)$.

O. P. P. Onitrev, N. N. Krasnov, G. A. Molin, and M. Y. Panaris, "Yields of $7_{B e}$ in the Irradiation of Lithium and Boron with Protons and Beuterons, and That of Beryllium with Protons, Deuterons, and a-Particles," Soviet At. Energy, 31, p. 876 (1972).

7. 6. W. Schweimer, "Fast Neutron Production with 54 MeV Deuterons," Mucl Phys, Al100, 636 (1967).

3. B. L. Cohen and C. E. Falk, "( $d, n)$ Reactions with 15-MeV Meutrons," Phys. Rev. 84, 173 (195i).

9. E. Tochlin and 6. 0. Kohler, "Neutron Beam Characteristics from University of Calffornia 60-inch Cyclotron," Health Physics 1, 332 (1958).

10. L. H. Smith and P. G. Kruger, "Thick Target Yields from the $(d, n)$ Reaction at $10 \mathrm{MeV}, "$ Phys. Rev. 83, p. 1137 (1951).

11. H. E. Crandall, G. P. Millburn, and a. Schecter, "Neutron Yields from Thick Targets Bombarded by 24 MeV Deuterons and 12 MeV Protons," Journal of App. Phys. 28, p. 273 (1957).

12. L. Schecter, "Angular Distribution of Neutrons from Targets Bambarded by 20 MeV Deuterons," Phys. Rev. 83, p. 695 (1951).

13. P. J. Persiani, "Neutron Source Considerations for the CTR Materials Program." Proc. of Workshop on High Intensity Neutron Generators, Las Vegas, Nevada, p. 111 , June 1972. 